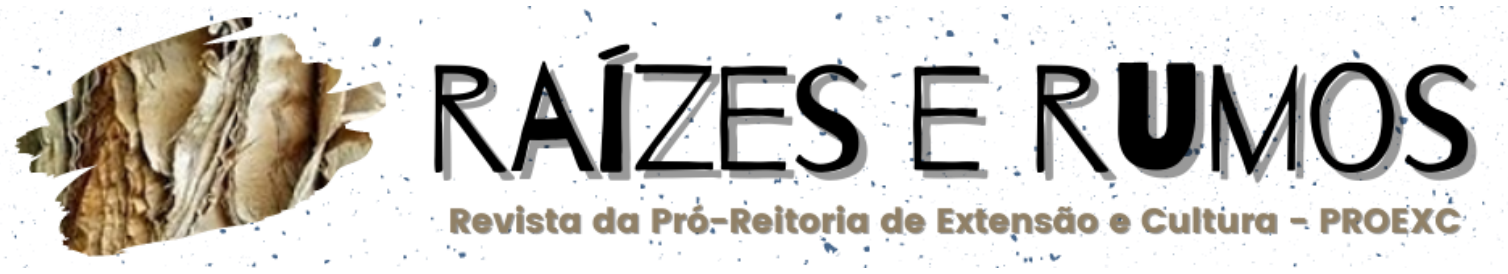

\title{
A educação das sensibilidades na extensão universitária: uma proposta lúdica e dialógica na ONG Atuação
}

The education of sensibilities in the university extension: a ludic and dialogic proposal in Atuação (NGO)

\author{
Laura de Paula Resende ${ }^{1}$ \\ Cláudio Guilarduci ${ }^{2}$ \\ Winnie Minucci ${ }^{3}$
}

\section{Resumo}

Este artigo objetiva apresentar e analisar as ações realizadas no programade extensão universitária Desempacotando a Biblioteca de São João del-Rei: Jogos, Brincadeiras e Teatro que tem sido executado na ONG Atuação, situada na cidade de São João del-Rei em Minas Gerais (Brasil). A proposta do programa visa efetivar uma prática artísticopedagógica focada na educação das sensibilidades e, também, na reflexão sobre os productos estéticos pedagógicos resultantes dessa prática. Serão analisadas as propostas executadas, no intuito de debater a forma como os estímulos são recebidos pelos participantes e quais reações expressas por eles. A partir de estudos acerca do papel do lúdico na infância, adentraremos em questões sobre as possibilidades subjetivas de se trabalhar o lúdico, este por si mesmo, como possibilidade de instigar a criticidade através da reconstrução da realidade.

Palavras-chave: Lúdico. ONG Atuação. Extensão universitária. Educação das sensibilidades.
Abstract
This article aims to present and analyze the actions carried out in the university extension program "Desempacotando a Biblioteca de São João del-Rei: Jogos, Brincadeiras e Teatro" (Unpacking the São João del Rei Library: Games, Playsand Theater), which has worked in the NGO Atuação, located in the city of São João del- Rei in Minas Gerais (Brazil). The purpose of the program aims to carry out an artistic- pedagogical practice focused on the education of sensibilities, and also on the reflection on the aesthetic pedagogical products resulting from this practice. The

\footnotetext{
${ }^{1}$ Discente do Programa de Pós-Graduação em Artes Cênicas da Universidade Federal de São João delRei (UFSJ) - lauraresende7@gmail.com

2 Docente do Programa de Pós-Graduação em Arte Cênicas da Universidade Federal de São João delRei (UFSJ) - guilarduci@ufsj.edu.br

3 Discente do Bacharelado em Teatro na Universidade Federal de São João del-Rei (UFSJ) winnieminucci@gmail.com
} 


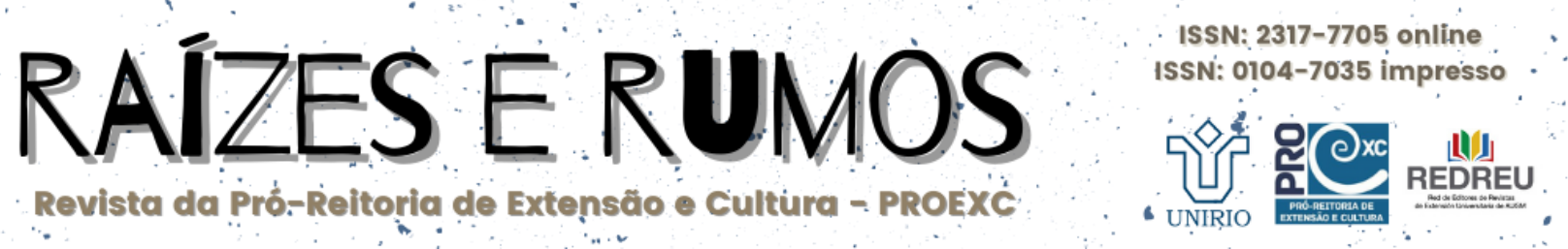

performed proposals will be analyzed in order to discuss how stimuli are received by the participants and what reactions are expressed by them. From studies on the ludicrole in childhood, we will address issues about the subjective possibilities of working the ludic, this by itself, as a possibility to instigate criticism through the reconstruction of reality.

Keywords: Ludic. ONG Atuação. University Extension. Sensitivity education.

\section{Introdução}

O programa Desempacotando a Biblioteca de São João del-Rei (Ano III) iniciou suas atividades em 2013 como projeto de extensão universitária do curso de Teatro da UFSJ. Coordenado pelo professor autor deste artigo e, desde o ano de 2015, funcionando como programa extensionista, vem se dedicando a investigar possibilidades de se trilhar caminhos para uma prática artístico-pedagógica capaz de estimular, durante o processo de ensino-aprendizagem, a Educação das Sensibilidades.Este conceito - que parte do corpo como ponto de convergência das emoções, sensações e sentimentos - busca meios pedagógicos com potencial para instigar o olhar crítico sobre essa convergência.

Por Educação das Sensibilidades entendemos as possibilidades pedagógicas que trabalham com o propósito de incluir e/ou problematizar as sensações, asemoções e os sentimentos como mecanismos de apreensão da realidade. A Educação das Sensibilidades, dito de outro modo, objetiva atuar no espaço pedagógico a partir da práxis, tendo o corpo como epicentro dessas pulsões e entendendo-o como a origem de onde brotam as reações diante da realidade. É nesse fazer que as sensibilidades possibilitam determinadas correspondências com o pensamento (PESAVENTO, 2007, p. 11-12).

A Educação das Sensibilidades parte do pressuposto de que o processo de ensino-aprendizagem vai além da compreensão racional e perpassa também o conjunto sensorial psicofísico do corpo, sem com isso estabelecer relações hierárquicas entre razão e emoção (PESAVENTO, op. cit., 12-14). Com esse objetivo em vista, a pesquisa que envolve o programa se debruça também sobre a reflexão 


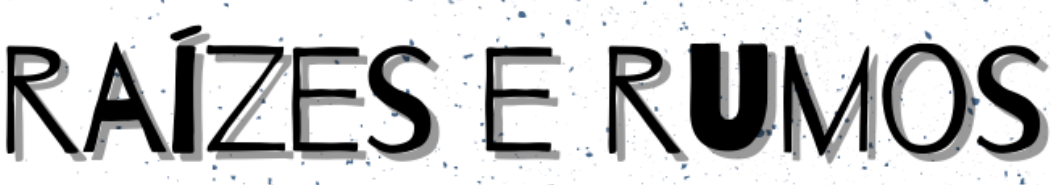

Revista da Prồ-Reitoria de Extenscio e Cultura - PROExĆ

acerca dos Pro-ductos estéticos pedagógicos ${ }^{4}$ desenvolvidos durante a prática de ensinoaprendizagem. É necessário repensar o que seria essa produção artístico-pedagógica diante de uma perspectiva que não visa uma finalidade produtivista mercadológica, mas que possuino "aqui-agora" da práxis um fim em si mesmo: encorajar o olhar sensível e crítico ao mundo.

Além disso, no pro-ducto estético pedagógico, mesmo refletindo as ações e os pensamentos realizados durante a execução de um determinado trabalho, deve-se priorizar a experiência de um "estar-no-meio" de coisas e ações, pois a nossa perspectiva pedagógica para realização das atividades do programa entende que as ações pedagógicas trazem sempre uma suspensão da ordem comum vivenciada pelos sujeitos a partir de um movimento duplo. Esse movimento, conforme nos apresenta Simons e Masschelein (2017, p. 55), indica o "trazer alguém para uma posição de ser capaz, que é ao mesmo tempo uma exposição para algo fora e, portanto, um ato de apresentar e expor o mundo". Nesse sentido, é revisto o significado da palavra "produto" em seu sentido etimológico latino de "conduzir para adiante", "orientar para o caminho a ser seguido".

Enquanto extensão universitária, compreendendo essa como a razão de ser das atividades acadêmicas, o programa extensionista entende que

a extensão é demarcada pelo contato proativo entre a universidade e a comunidade, ou seja, o contato com a comunidade não é uma possibilidade, mas o principal motor das atividades acadêmicas. E não se trata de um contato para simplesmente levar o conhecimento científico resultado da pesquisa e do ensino aos menos favorecidos, mas a possibilidade de repensar o próprio conhecimento científico e a formação acadêmica a partir de sua atuação. (GUILARDUCI; BAPTISTA, 2018, p. 9)

O programa Desempacotando a Biblioteca tem atuado, desde 2016, em parceria com a organização não governamental (ONG) Atuação - sediada no bairro Tijuco, em São João del-Rei, Minas Gerais, Brasil - que se dedica a criar políticas públicas e ações socioculturais que promovam a integração, a diversidade e o desenvolvimento

4 GUILARDUCI, C; TALARICO, O. Pro-ducto estético pedagógico: uma (des)construção das percepções sensoriais (113-127). As letras da política. Rio de Janeiro, Mauad X. 2015. 


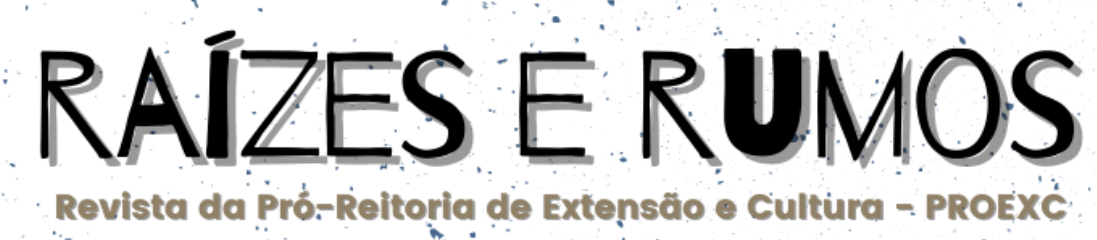

- ISSN: 2317-7705 online ISSN: 0104-7035 impresso

humano, sobretudo dos moradores do bairro. Ali, o programa se encontra com a comunidade externa e, também, com setores à margem da sociedade, dedicando-se a oferecer oficinas de teatro, jogos teatrais e brincadeiras coletivas paracrianças e préadolescentes entre oito e treze anos.

Tanto a ideia de Educação das sensibilidades quanto o termo pro-ducto estético pedagógico trazem apropriações dos conceitos trabalhados por Walter Benjamin e, especificamente, no presente programa, a apropriação ocorre a partir da sua obra Rua de mão única (1995), cujo fragmento “O caráter destrutivo" (p. 235-237) nos é precioso auxiliar metodológico ao longo da presente reflexão sobre os trabalhos realizados na ONG Atuação. Este recorte conceitual é importante referencial metodológico para pensar a prática pedagógica realizada na ONG Atuação e também serviu como norteador metodológico para elaboração da oficina "Jogos, Brincadeiras e Teatro", ministrada pelas bolsistas do programa, oferecida no $30^{\circ}$ Inverno Cultural da Universidade Federal de São João del-Rei, entre os dias 23 e 25 de julho de 2018, e que será analisada neste artigo.

\section{O caráter destrutivo e sua atuação no terceiro setor}

Na obra de Walter Benjamin (1995, p. 235-237) o caráter destrutivo aparece como a ideia de combate a tudo aquilo que está estabilizado, intocado e conservado como verdadeiro para abrir caminhos, novas possibilidades que se cruzam contrapondo-se a uma rua de direção única ou a construção de um único caminho. Ocaráter destrutivo valoriza o potencial das situações e assegura o pensamento dialético, por isso seu adversário é o "homem-estojo", o burguês que vive aprisionado em sua "moradia-estojo" com a promessa de felicidade. Esse interior que cria a imagem de aconchego, conforto e segurança é o mesmo que o resultado de um raciocínio tecnocrático que busca acondicionar com perfeição seus moradores causando uma privação da vida pública.

O burguês, para Benjamin (1995), aspira fazer da sua morada um museu que reúne, no conforto da sua casa, uma coleção para que ele possa contemplar o mundo 


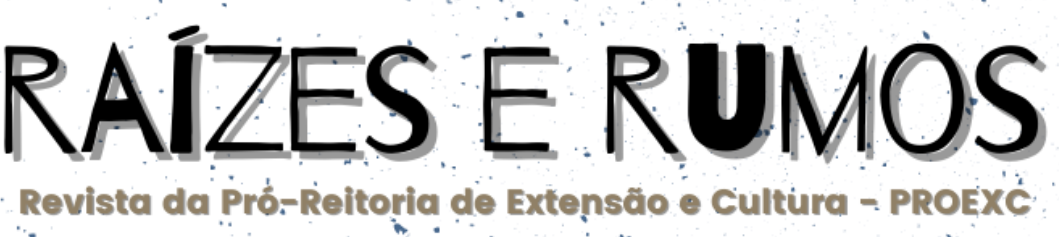

ISSN: 2317-7705 online

a uma distância confortável. A acumulação de bens, de acordo com Bolle (2000, p. 379) é a representação desse "homem-estojo", um colecionador que se torna uma espécie de "flâneur congelado".

O caráter destrutivo tem a consciência do homem histórico, cujo sentimento básico é a desconfiança insuperável na marcha das coisas e a disposição com que toma conhecimento de que tudo pode andar mal. Por isso, o caráter destrutivo é a confiança em pessoa (BENJAMIN, 1995, p. 236-237).

O surgimento da potência renovadora, portanto destrutiva, urge quando a imobilidade, o acomodamento e a conservação das estruturas sistêmicas culminam no abandono, na ineficiência e na ausência de atuação do poder público diante dos problemas sociais que afetam determinadas parcelas da população. Por esta perspectiva é que o Terceiro Setor, já, há algum tempo, vem se consolidando como uma espécie de resposta ágil ao que parece ser essa urgência de renovação/destruição: ter o poder de intervir na estrutura e transformar sua ação em impactos no contexto social. Geralmente, as ações relacionadas a essas organizações reverberam a voz de um determinado grupo social que testemunha cotidianamente o engessamento das estruturas do poder público e o distanciamento de suas ações em relação a esse mesmo grupo, que percebe “a olhos nus" a força centrífuga que o empurra cada vez mais para longe das ações do Estado.

O Terceiro Setor pode ser entendido como uma complexa rede formada por instituições, fundações, associações comunitárias, organizações não governamentais (ONGs) e entidades filantrópicas, cuja constituição se dá por iniciativas privadas sem fins lucrativos frente às ações que executam (MENDES, 1999, p. 6-8).

Segundo o Censo do Instituto Brasileiro de Geografia e Estatística (IBGE) de 2010, o Bairro Tijuco - no qual está sediada a ONG Atuação - além de ser considerado um dos bairros mais tradicionais da cidade, tem sua população estimadaem 15.699 habitantes, sendo o segundo maior bairro do município de São João del- Rei e com o maior número de crianças e jovens da cidade. A ONG Atuação, fundadaem 17 de março de 2005, se materializa pela criação do Pré-Vestibular Comunitário Atuação, 


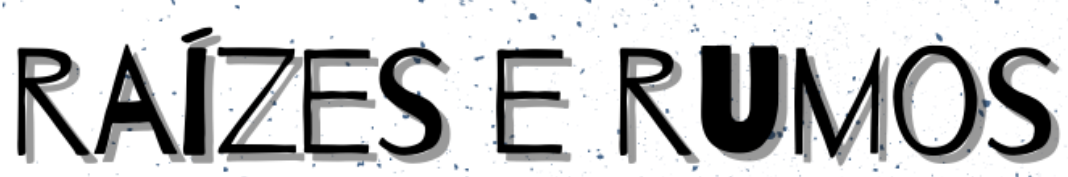

Revista da Prồ-Reitoria de Extensąo e Cultura - PROEXĆ

que contou com grande empenho da população que reside no município, especialmente a do seu bairro e, também, com o apoio da direção da Escola Estadual Professor Iago Pimentel, localizada no mesmo bairro.

O espaço de convívio da ONG surge na intersecção construída entre colaboradores voluntários e contratados, profissionais ou pessoas em profissionalização, pessoas no cumprimento de medidas penais e/ou socioeducativas mediadas pela justiça, estudantes das escolas públicas do bairro que buscam ali atividades extracurriculares e demais pessoas que eventualmente encontram na ONG algum tipo de suporte institucional capaz de suprir a ausência ou a ineficácia que marca a relação do poder público com o bairro onde a ONG está sediada.

\section{O lúdico nos jogos teatrais}

Enquanto prática que possui um fim em si mesmo, capaz de suscitar momentos de transformações da realidade, o jogo teatral e as brincadeiras dirigidas surgiram nocontato com as crianças e pré-adolescentes que frequentam a ONG, como elemento-chave tanto para a percepção dos contextos aos quais as meninas e meninos estão inseridos, quanto para despertar neles a vontade de transformação.

O desafio que emerge, no entanto, é o de encontrar a medida justa durante as oficinas, capaz de instaurar a ludicidade no ínterim das relações. Uma vez que o jogo se apresenta enquanto prática, a condução dos jogos, pelas bolsistas, passa a cuidar de oferecer aos participantes a autonomia necessária para que eles mesmos alterem as regras do jogo em benefício da manutenção da ludicidade instaurada. Importante ressaltar aqui que cada jogo proposto não visa metas objetivas, nem estimular nada mais que as próprias relações sociais das crianças e dos pré-adolescentes, entendendo-se a Educação das Sensibilidades, aqui, como a possibilidade, através do lúdico, de despertar, mesmo que por instantes, o olhar crítico para a relação $\mathrm{eu} /$ mundo.

Ressaltando, via de regra, conforme salienta Guilarduci e Baptista (2018), que 


\section{RAIZZES E RUMOS \\ Revista da Pró-Reitoria de Extenscio e Cultura - PROEx'́̀

“existe na realidade, um adestramento do lúdico na tentativa de fazer da brincadeira, do jogo, um instrumento que deve preparar a criança para a seriedade futura" (p. 17), os jogos e brincadeiras propostos pelas bolsistas tentam evitar ou subverter lógicas de relações já cristalizadas no comportamento das crianças e préadolescentes. O espírito de competição - que muitas vezes emerge na pergunta "quem sair, perde?" - levando diversas vezes à associação da derrota ao fracasso, a imposição da ordem pela força, o entendimento do espaço do jogo como espaço a ser conquistado, ou mesmo a autonomia de transformar as regras entendidas como ganho de poder, sãoexemplos dos perigos e dos pontos de tensão capazes de desequilibrar as relações lúdicas estabelecidas pelos jogos. O olhar dialógico surge então nas relações entre as bolsistas e as crianças e adolescentes participantes ao perceberem os paradigmas socioculturais que se infiltram no lúdico e tentar rompêlos através do próprio lúdico, tendo em vista que

A imposição de uma regra externa que pretenda garantir o resultado final da atividade lúdica é tão danosa quanto a crença de que o lúdicoé indomável. Não se trata apenas de uma questão fisiológica e instintiva. Mesmo que parta de uma necessidade instintiva de aprender a sobreviver no mundo, o lúdico se desenvolve com a astúciada experiência, ultrapassando a sua motivação arquetípica. É nesse ambiente em que o lúdico ultrapassa o seu impulso fisiológico que é possível pensar em uma atuação pedagógica. (GUILARDUCI; BAPTISTA, 2018, p. 19)

Os desafios de se manter a ludicidade em equilíbrio, fugindo dos paradigmas socioculturais que cercam a realidade dos participantes, imprimiu às oficinas e aos próprios jogos não um caráter de adestramento e disciplinamento das relações, mas um exercício de "astúcia e arrogância", no sentido benjaminiano5, capaz de enfrentar uma estrutura de poderes da qual as crianças e pré-adolescentes talvez não saibam dimensionar, mas dentro da qual já estão inseridos.

\footnotetext{
${ }^{5}$ Termo referente à corrente de pensamento associada aos estudos do filósofo alemão WalterBenjamin, neste caso, às teorias do filósofo sobre educação. Maiores explicações ver o artigo: GUILARDUCI, Cláudio. Em busca da felicidade perdida: a astúcia e a arrogância no caminho da iluminação profana. Diacrítica, [S.L.], v. 31, n. 2, p. 23, 3 out. 2018. University of Minho. http://dx.doi.org/10.21814/diacritica.232.
} 


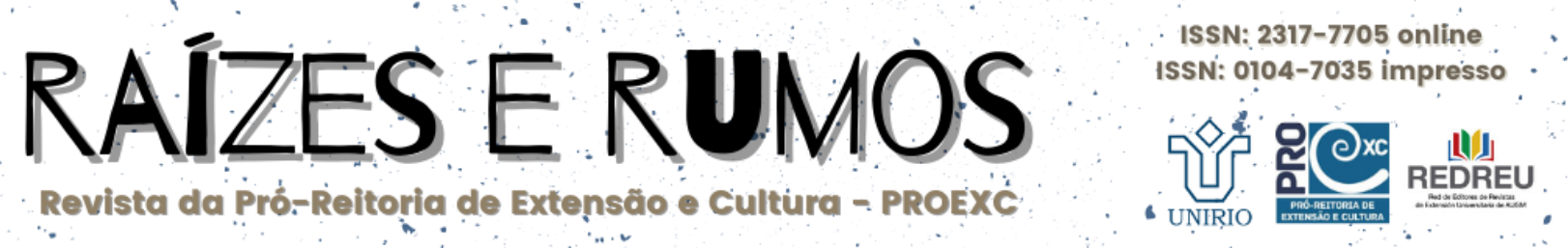

\section{A oficina "Jogos, brincadeiras e teatro" no $30^{\circ}$ Inverno Cultural da UFSJ}

O Inverno Cultural é um evento de grande reconhecimento que acontece anualmente em São João del-Rei e conta com diversas atividades culturais como shows musicais, espetáculos teatrais, exposições, intervenções e oficinas. O evento é realizado pela Pró-Reitoria de Extensão Universitária (Proex) da UFSJ e tem tido impacto positivo tanto para a vida acadêmica de estudantes da Universidade quanto para a população do município por contar com intensa movimentação artística e cultural que almeja a descentralização desses acontecimentos.

A partir de reflexões sobre os trabalhos já realizados e que são fruto da parceria entre o projeto de extensão aqui abordado e a ONG Atuação, tomando por base relatos de participantes que já passaram pelo projeto, somados às percepções das bolsistas que propuseram a realização do trabalho, foi vista a necessidade de refletir sobre possibilidades metodológicas e estruturais que viabilizassem um melhor aproveitamento das atividades oferecidas na programação oficial do $30^{\circ}$ Inverno Cultural da UFSJ.

Diante de um cenário muitas vezes excludente e não representativo, a ideia foi manter a oficina no espaço da ONG Atuação, voltando-a exclusivamente para o seu público, na busca por garantir e facilitar o acesso da população frequentadora da ONG, que é o público-alvo da oficina. Essa decisão se deu ponderando-se as possibilidades reais de que as crianças e adolescentes usuárias da ONG Atuação fossem as principais beneficiadas e responsáveis pela construção da oficina. Para isso, levamos em conta fatores como a facilidade de locomoção, visando o públicoalvo que reside em sua maioria no bairro onde está localizada a sede da ONG Atuação. Também foram discutidos fatores que dizem respeito ao sentimento de pertencimento que as crianças já possuem em relação a este espaço.

Entendemos a necessidade de romper com barreiras simbólicas que ainda segregam os espaços acadêmicos e que partem da ideia de que o espaço da Universidade atende somente a uma elite socioeconômica e ignora as diversidades. Essa visão precisa ser revista e é de extrema importância que existam políticas públicas que assegurem o direito de todas as pessoas estarem nesse espaço que antes 


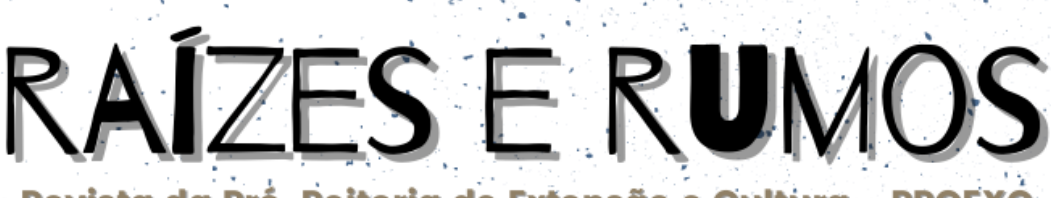

Revista da Prồ-Reitoria de Extensąo e Cultura - PROEX⿳亠

fora segregado. Apesar de entender a universidade como um lugar do povo, neste primeiro momento decidimos por fortalecer a noção de pertencimento em relação a ONG Atuação como um espaço potente para a transformação.

\section{Detalhamento da metodologia utilizada na oficina}

A partir de tais observações sobre o Inverno Cultural e os espaços acadêmicos e não acadêmicos, pensamos sobre as possíveis maneiras de orientar a oficina de modo que essa contemplasse tanto as crianças e adolescentes que já participaram das atividades que são realizadas semanalmente pelo programa, quanto crianças e adolescentes que ainda não conheceram o trabalho que está sendo executado. Nesse sentido, optamos por realizar a oficina com base no método dos viewpoints, buscando aliar jogos e brincadeiras já presentes no cotidiano infantil aos exercícios de improviso que este método possibilita.

O método dos viewpoints foi desenvolvido primeiramente pela bailarina Mary Overlie e posteriormente reformulado por Anne Bogart (2017). Trata-se de um método recentemente desenvolvido e que propõe exercícios que exploram diversas possibilidades de composição de movimento a partir de variações de tempo e espaço. Por ser um método de fácil adaptação e que trabalha a partir de percepções sensíveis, esse pode contemplar diferentes públicos com realidades e idades distintas, como é o caso do público-alvo da oficina.

Uma das propostas que marcam a práxis dos trabalhos realizados em cooperação com a ONG Atuação, se deu por meio da criação de uma rotina de exercícios que eram repetidos semanalmente nos momentos de abertura e encerramento das atividades. Esses consistem em exercícios de escuta, relaxamento, atenção e reflexão. Além desses momentos de abertura e encerramento, nos dias em que se realizou a oficina que integrou o $30^{\circ}$ Inverno Cultural da UFSJ, foram executadas outras propostas de jogos e brincadeiras construídas a partir de exercícios que hibridizavam o método dos viewpoints com brincadeiras lúdicas do cotidiano infantil, tendo como pano de fundo os conceitos de Educação das 


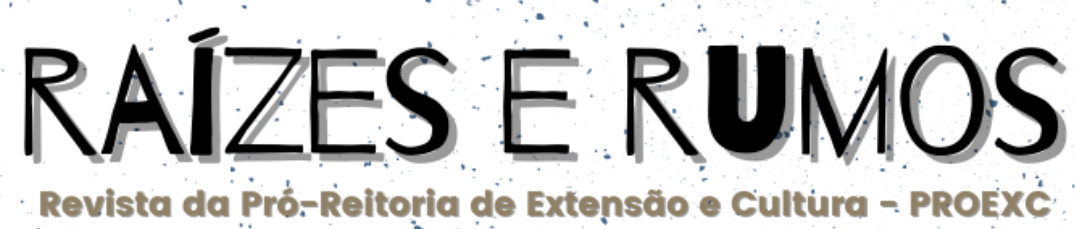

- ISSN: $2317-7705$ online ISSN: 0104-7035 impresso

sensibilidades e os pro-ductos estéticos pedagógicos. No primeiro dia foi feito um aquecimento lúdico utilizando balões sob a orientação de rebater os balões experimentando diferentes partes do corpo, com o objetivo de não deixar os balões caírem no chão. Após esse exercício e aproveitando os balões que estavam sendo utilizados, propusemos um momento de observação atenta e sensível desse objeto queé comum de nosso cotidiano e que pode ser visto como rico em possibilidades lúdicas.Em seguida, as crianças foram orientadas a caminhar pelo espaço e explorar diferentes formas de percorrer pequenos percursos (linhas, curvas, velocidades, planos etc.).

Em contraste a essas atividades, propusemos um momento de maior relaxamentono intuito de estimular a imaginação, a criação de imagens e situações que acontecem tanto na realidade cotidiana quanto nos sonhos. As crianças se acomodaram e fecharam os olhos enquanto ouviam a história de Alice no país das maravilhas, que foi narrada e musicalizada pelas proponentes. Ao final da contação, as crianças despertaram e responderam algumas perguntas que lhes foram feitas. Tais perguntas eram sinestésicas e pediam para que associassem uma cor, um cheiro e uma textura que remetesse à história contada. Para finalizar, cada criança criou uma cena,imagem ou ação que dialogava com o livro Alice no País das maravilhas, estando, para isso, livres para fazer uma adaptação fiel, simbólica ou que ressignificasse a narrativa. No segundo dia de oficina, retornamos ao exercício de percorrer pelo espaço experimentando formas diferentes de caminhar de acordo com orientações dadas, sendo acrescentado um estímulo diferente que consistia em andar observando osdetalhes. Em certos momentos, durante esse exercício, pedíamos para que todos parassem e perguntávamos sobre algum detalhe do espaço a uma das crianças participantes. Em seguida, foi proposto um jogo que consistia em formar sequências numéricas da disposição de um dado utilizando somente os corpos e as disposições espaciais. Ambos os exercícios tinham por objetivo ativar um pensamento estratégicoe de trabalho em grupo a partir de estímulos capazes de incentivar a atenção. A proposta seguinte consistiu em um jogo denominado "quadrados de emoções", em que cada participante desenhava um quadrado no 


\section{RAIIZESE RUMOS \\ Revista da Prồ-Reitoria de Extensąo e Cultura - PROEXĆ}

chão e escrevia uma emoção de sua escolha dentro. Esses quadrados serviam para guiar movimentos improvisados que se realizavam de acordo com a emoção escolhida.

Após explorar composições de movimentos criados com base nas emoções escritas, propusemos um jogo de integração nomeado como “Vu! Há! Blim!". Esse jogo consiste em uma troca ativa de movimentos que trabalham a atenção e a escuta, e funciona da seguinte forma: o grupo posiciona-se em círculo e uma pessoa inicia o jogo lançando os braços para frente direcionados para outra pessoa ao mesmo tempo em que diz “Vu!". Em seguida a pessoa para qual a primeira se direcionou com o “Vu!"ergue os braços ao mesmo tempo em que responde com "Há!" e a partir de então as duas pessoas que se encontram ao lado da que recebeu o "Há!" fazem um movimento de corte com os braços enquanto pronunciam “Blim!". Este jogo foi feito no intuito de ativar as percepções para as próximas propostas que encerrariam mais um dia de oficina.

Para as atividades finais, passamos orientações para que o grupo de participantes construíssem paisagens sonoras da seguinte forma: dividimos grupos de quatro pessoas em que cada grupo precisaria escolher um espaço qualquer (externo à $\mathrm{ONG}$ ) para construir a sonoridade dos acontecimentos cotidianos daquele espaço. Na primeira versão a sonorização foi produzida utilizando apenas os corpos como instrumento e na segunda versão foram concedidos alguns instrumentos de sopro e percussão para serem utilizados.

No terceiro e último dia repetimos o jogo de integração em círculo “Vu! Há! Blim!" e somamos a esse outro jogo que segue uma mesma lógica estrutural, que chamaremos aqui de "Yá! Rondom! Xita!". Esse funciona da seguinte maneira: em círculo, um a um estende a mão para a pessoa que se encontra ao seu lado direito ao mesmo tempo em que exclama "Yá!" e assim sucessivamente até que esses movimentos se tornem fluidos. A partir de então é introduzido outro comando que consiste em interromper esporadicamente a sequência de "Ya!" com um movimento de puxar os braços para trás e pronunciar "Rondom!" que serve para inverter o sentido (horário ou anti-horário) dos movimentos sendo que o "Yá!" continua para 


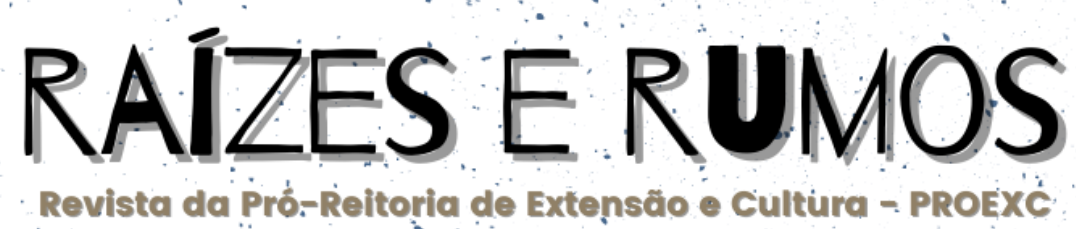

- ISSN: 2317-7705 online ISSN: 0104-7035 impresso

a outra direção. Novamente, quando o jogo se torna fluido, é inserido o comando de "Xita!" permitindo que cada participante possa se direcionar não só para quem está ao seu lado, mas para qualquer pessoa do círculo. Para isso, é preciso que a pessoa participante lance os braços para a direção de alguém enquanto pronuncia “Xita!" e flexione levemente os joelhos e a pessoa para qual esta se direcionou é que decide como proceder com o jogo, podendo utilizar de “Yá!”, “Rondom!” ou “Xita!" e assim sucessivamente.

Acrescentamos a esses jogos características de variação de intenção que poderiam ser expressos corporalmente com mudanças de altura, velocidade e emoção. Aproveitando a formação de círculo, nos sentamos e propusemos um jogo que trabalhava a memória e que já possuía estrutura conhecida por algumas das crianças. Nesse jogo começávamos dizendo: “no meu zoológico tem!" - e acrescentávamos um animal - e assim sucessivamente até que todas da roda tivessem falado os animais já ditos pelas pessoas anteriores e acrescentado um de sua escolha. Em seguida, nos levantamos e ainda em roda propusemos a criação de movimentos onde cada um sugeria um movimento de sua escolha que era repetido por todas as pessoas até que se configurasse um tipo de "coreografia" criada a partir da contribuição de todos.

Com o aquecimento desses corpos, orientamos novamente a caminhada pelo espaço e introduzimos uma linguagem simbólica a partir de sílabas soltas e picadas em que se podia "entender" o que era dito apenas por via de expressão corporal potencializada. A história de Alice no país das maravilhas foi recontada, dessa vez, de forma sintética e diferente da primeira contação, uma vez que, foram as crianças e adolescentes ouvintes que compuseram a musicalidade. A partir disso, e como atividade final foram divididos grupos menores e cada grupo teve como tarefa produzir uma cena curta a partir da história e que tivesse, ao invés da linguagem comum falada, a linguagem testada no exercício anterior.

Para o encerramento da oficina foi sugerido que cada participante gravasse um curto vídeo contando como foi a experiência de participar das atividades, do que mais gostaram, do que não gostaram e também que dessem sugestões sobre o que 


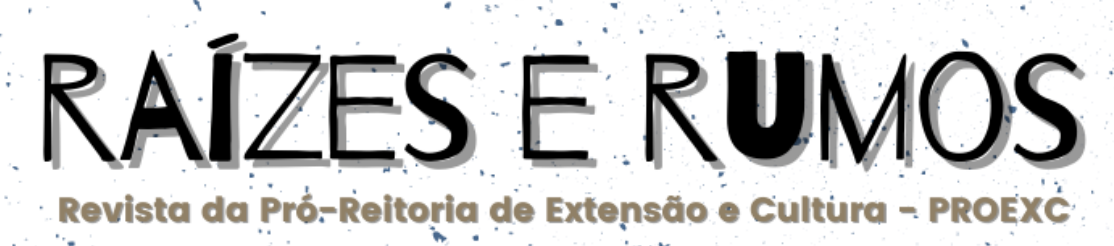

- ISSN: 2317-7705 online ISSN: 0104-7035 impresso

poderia ser feito de diferente. Esse retorno é de grande importância para que possamos refletirsobre o que foi executado e buscar maneiras para melhorar o desempenho das atividades, estimulando, assim, o diálogo entre comunidade acadêmica e comunidade externa.

\section{Resultados}

O retorno obtido das pessoas envolvidas na oficina, tanto crianças como pessoas que passaram pelo espaço durante a realização nos mostra um olhar atento e curioso da comunidade para o trabalho que está sendo feito, característica que julgamos ser um dos motores geradores para a realização do projeto nesse espaço. Alguns dos comentários feitos pelas crianças e adolescentes que aparecem nos vídeos gravados no último dia da oficina mostram esse olhar atento, ativo em busca de conhecer algo novo.

Duas das crianças participantes apontaram que a atividade que mais as agradaram foi a que envolvia a experimentação musical utilizando instrumentos antes desconhecidos pelas mesmas. Outra participante relatou ter gostado e achado bastante relevante o momento de composição de movimentos, chamando a atenção para o fato de essa atividade ter sido acompanhada com a reprodução de música clássica.

Sobre a educação das sensibilidades e o trabalho com os afetos, pudemos observar as emoções reais que foram trazidas pelas crianças e que demonstram a realidade na qual estão inseridas. Durante o jogo dos quadrados com emoção, por exemplo, apareceram gestos e frases que remetiam à religiosidade, ao amor romântico e à violência. $\mathrm{O}$ afeto foi estimulado durante as oficinas pela ludicidade das atividades, pela metodologia que envolve emoções, mas também pela relação estabelecida entre quem estava conduzindo a oficina e quem participava e se deixava ser conduzido.

Acreditamos que momentos de abstração e descanso são importantes para um melhor aproveitamento das atividades e, para isso, a possibilidade encontrada 



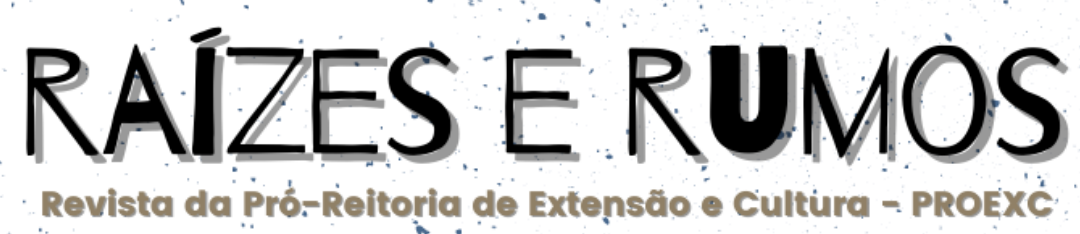

- ISSN: 2317-7705 online ISSN: 0104-7035 impresso Revista da Pró--Reitoria de Extensço e Cultura = PROEXC

Fundamentado na ideia de educação das sensibilidades como possibilidade de se trabalhar num equilíbrio entre razão e emoção, partindo do entendimento sobre o "caráter destrutivo" como ferramenta fundamental na práxis é que construímos a oficinaque foi ministrada no $30^{\circ}$ Inverno Cultural da UFSJ. A oficina se realizou de forma positiva, considerando os moldes dialéticos pela qual foi pensada e fazendo acontecer proposições estéticas que partiram dos corpos ativos das crianças participantes.

A ideia que envolve o conceito de pro-ducto estético pedagógico foi debatida em encontros que antecederam e precederam a oficina entre bolsistas e coordenador como intuito de discutir e refletir a práxis. É de expectativa do senso comum que trabalhos com práticas artístico-pedagógicas resultem em um produto final, algo para ser mostrado/apresentado. Essa expectativa nos faz perceber a função comercial de produção difundida no meio artístico educacional, noção essa que não contemplamos, mas que em contrapartida buscamos mostrar outras possibilidades arte-educativas capazes de transformar as realidades individuais e coletivas de quem participa.

Por essas razões, a oficina priorizou o estado presente, ou seja, propôs vivenciar o "aqui-agora" em contrapartida à idealização de um produto final a ser mostrado numtempo futuro. A experiência de "estar-no-meio" é prioridade das práticas pedagógicas propostas pelo programa de extensão universitária aqui abordado, sendo que a circulação de pessoas que frequentam e/ou colaboram com a ONG Atuação, assim como o olhar atento de transeuntes que passavam pela rua e se voltavam por instantes para observar as atividades constroem a experiência do fazer artístico objetivado pela proposta dialógica da extensão universitária.

\section{Referências}

BENJAMIN, W. Rua de mão única. São Paulo: Brasiliense, 1995.

BOGART, A; LANDAU, T. O livro dos viewpoints: Um guia prático para viewpoints ecomposição. São Paulo: Perspectiva, 2017. 
BOLLE, W. Fisiognomia da metrópole moderna: representação da história em Walter Benjamin. São Paulo: Editora da Universidade de São Paulo. 2000.

GUILARDUCI, C; BAPTISTA, M. R. O lúdico na educação: a questão do método. Baptista, M. R. (Org.). Ludicidade e educação: Diálogo. Barbacena: EdUemg, 2018.p. 17-31.

GUILARDUCI, C; TALARICO, O. Pro-ducto estético pedagógico: uma (des)construçãodas percepções sensoriais (113-127). As letras da política. Rio de Janeiro, Mauad X. 2015.

GUILARDUCI, Cláudio. EM BUSCA DA FELICIDADE PERDIDA: a astúcia e a arrogância no caminho da iluminação profana. Diacrítica, [S.L.], v. 31, n. 2, p. 23, 3 out. 2018. University of Minho. http://dx.doi.org/10.21814/diacritica.232.

PESAVENTO, S. Sensibilidade: escrita e leitura da alma. In: PESAVENTO, Sandra; LANGUE, Frédérique (Orgs.). Sensibilidades na história: memórias singulares e identidades sociais. Porto Alegre: Editora da UFRGS, 2007, p. 9-21.

SIMONS, M; MASSCHELEIN, J. Experiências escolares: uma tentativa de encontrar uma voz pedagógica. LARROSA, J. (Org.). Elogio da escola. Tradução Fernando Coelho. Belo Horizonte, Autêntica. 2017, p. 41-63. 